\title{
Course Reform of Mobile Device Programming for Information Management and Information System
}

\author{
Yang Xiao ${ }^{1,}$, , Yang Jing ${ }^{2, b}$ \\ ${ }^{1}$ School of Management Science and Engineering, Shandong University of Finance and Economics, \\ Jinan, 250014, China \\ ${ }^{2}$ School of Applied English Studies, Shandong University of Finance and Economics, Jinan, 250014, \\ China \\ aemail: sdufeyangxiao@163.com, bemail: yangjing8124@163.com
}

Keywords: Course Reform; Mobile Device Programming; Information Management and Information System

\begin{abstract}
Although the specialty of information management and information system has already started mobile development courses, the current course orientation is not clear, and therefore the teaching plan, teaching content and experiment plan are not targeted. Aiming at this problem,we studies the teaching purpose and content of the mobile development course for specialty of information management and information system, and designs the experimental case base of information management and information system. By proposing training program for mobile device information system design curriculum, we designs and improves information system case base for mobile device, making students majoring in information management and information system master the basic function of mobile development, and design and develop multiple system oriented information system client and server. For information management and information system majors who have good information system development capabilities, they need not to increase investment in hardware and software or modify other teaching content. They can easily transfer to mobile platform oriented information system design and development, integrating with other development technology course as a whole, so as to improve the current isolating situation of mobile development technology course.
\end{abstract}

\section{Introduction}

Mobile Internet is one of the world's greatest potential industry today, an important aspect influencing the five elements of IT technology and industrial development which are cloud computing, Internet of things, mobile Internet, big data and smart city. In recent years, the mobile normalization construction of various e-commerce websites, enterprises, banking and sectors has moved into a period of rapid development, with mobile applications like "Taobao Client", "Mobile Government", "Mobile Tax" appearing through 3G and other mobile wireless network for data transmission. The emergence of these mobile applications allow users to complete the related business with mobile phones or other mobile terminals thus making shopping, administration unrestrained by place and space, which greatly improves the efficiency of trade and official business.

According to "2014 Mobile Internet Industry Compensation Investigation Report" [1], in the next two years, almost all companies involved in the survey are in demand for mobile development talents, including a strongest demand for Android development engineer (more than $85.8 \%$ of the participating companies have a demand for such talents), followed by IOS engineers and Amazon architects.

The scarcity of mobile development talents caused a higher pay for mobile developers than other similar development technicians [2]. According to the research report [1], the starting monthly salary for graduates in first-line companies has exceeded 8,000 yuan while in famous enterprises like Huawei, ZTE and Tencent it is 10,000 yuan or more. Most small and medium-size enterprises offer more than 5,000, far outstripping other industries and enterprises. 
Nevertheless, the present courses of specialty of information management and information system, such as "Information System Design and Practice" and "Object-oriented programming language", mainly focus on the development and design of desktop or traditional Internet platform information system development, which is either basically fading away from the market or saturated the market demand. The aging course leads to a disjunction between students' learning and social needs, resulting in a decrease of employment rate of information management and information system majors year by year [1]. While the development of mobile internet application for mobile Internet mobile terminals is in the ascendant, there is a large market demand. The rapid development of mobile Internet has brought new opportunities and challenges for the development and personnel training of the specialty of information management and information system. How to modify the teaching plan and teaching content to comply with the tide of mobile Internet and enhance the employability of students is a problem that needs to be solved urgently.

Specialty of mobile Internet is not included in the current general university education catalog, but mobile development courses have been opened. MOOC coursera has started iOS oriented Objective-C and Android system oriented Android mobile development courses. To set up mobile development courses have already become the norm, thanks to Google Android academic cooperation program initiated in 2011. But now mobile development courses are mainly about the universality of mobile application development, such as image viewer, address book development, calculator development, without information system development of mobile terminals for Information Management and Information System majors.

\section{Related Works}

Directed against the difficult employment situation of Information Management and Information System Majors, scholars have put forward a series of improvement actions: Zhang Yunpeng [3] analyzed the present situation of college information management and information system specialty construction; Li Hongxia [4] proposed a project-driven teaching mode of management information system; Xiao Yong [5] probed into the course arrangement of information management and information system specialty.

Niu $\mathrm{Li}$ et al. [6] investigated methods to cultivate innovative and entrepreneurial talents by school-enterprise integration in higher vocational colleges through IOS mobile development platform. Li Xinhui et al. [7] suggested that Android mobile application development course should follow "learning by doing": first fit knowledge and skill points into the actual program, and then allow students to practice after theory, to learn by doing. The above mentioned literature on mobile development course teaching reform mainly emphasizes how to improve students' ability from a practical point.

Since the market's demand for network-oriented B2C talents has been basically saturated, how to find employment opportunities for the Information Management and Information System majors is a key issue to be solved. Mobile terminals oriented information system development provides a very good way out for the Information Management and Information System students, which needs more originality than programming, and therefore more suitable for secondary college students such Yanshan College of Shandong University of Finance and Economics.

\section{Course Design of Information Management and Information System Mobile Device Program Development}

\section{Teaching Content of Information Management and Information System Mobile Device Program Development}

The training objective of the course is to cultivate information system development personnel on the smart mobile platform in order to meet the need of banks, enterprises and other mobile information system development requirements. To achieve this goal, it is necessary to make full use of current information system design course of the specialty of information management and information system, and create a unique mobile development course. 
For the current mobile development course lack pertinence, syllabus of the specialty of information system in domestic and foreign famous universities as well as MOOC cousera are investigated to bring in and transform the relevant teaching mode to adapt our students and the specific situation. In accordance with international standards, the course syllabus is fully updated to enable the course content completely conform to the forefront of industry standards.

Specifically, the teaching content includes the following aspects (Figure 1):

\begin{tabular}{|c|c|c|c|c|}
\hline $\begin{array}{c}\text { Android System } \\
\text { Overview }\end{array}$ & $\begin{array}{l}\text { Android B } \\
\text { Contro }\end{array}$ & & nced & Multithreading \\
\hline $\begin{array}{l}\text { Images and } \\
\text { Multimedia }\end{array}$ & Data Storage & $\begin{array}{l}\text { Network } \\
\text { Access }\end{array}$ & Bro & $\begin{array}{l}\text { ast, Service and } \\
\text { tent Provider }\end{array}$ \\
\hline \multicolumn{4}{|c|}{$\begin{array}{c}\text { Comprehensive Cases of Android Information System } \\
\text { Development }\end{array}$} & \\
\hline
\end{tabular}

Figure 1. Course structure of mobile application development technology

(1) Android System Overview: structure of Android system, construction of Android development platform, four components of Android system.

(2) Android interface design: Use of Android basic control and advanced control, concept and application of monitor, ArrayAdapter, BaseAdapter and other adapters.

(3) Graphic design: how to draw two-dimensional graphics, how to draw the image in Android.

(4) Multi-threading: drawing dynamic graphics and images with threads and timers.

(5) Data storage: SharedPreferencen, SQLite and other data storage.

(6) BroadcastReceiver, Service and ContentProvider.

(7) Comprehensive Cases of Android Information System Development.

Because Android development platform can be developed in the Windows environment, the development tools Android Studio can be download for free. The low learning cost and the existing experimental condition can meet the basic needs of the general application development. With this mainstream mobile platform Android operating system as the starting point, through course and case study, students can master the basic characteristics, the basic process and basic methods of mobile Internet application development, and understand the operating system-based application development, deployment, management and other advanced smart phone software development technology. An information system development case, such as library management system, can serve as the main line to connect each knowledge point.

\section{Construction of mobile device information system experimental case base}

As a practical course, the experimental aspect is very important for the mobile development course. The appropriate project case design is a key issue in teaching content and lab experiment to enable students to understand the course content and carry out experiments. Gradual penetration of new knowledge in practice is required so that students can perceive the cause and process when specific technologies are applied in the actual scene. Teaching cases and experimental cases can have options of mobile libraries, mobile banking and other mobile office automation system, or student course selection assistant.

Projects and cases for teaching and experiments should be selected according to the students' ability of programming, and the workload should grow from small to large, from easy to difficult, handy and interesting. To be specific, at the beginning of the course teaching cases and experimental cases may include the following types:

UI interface and event handling: for teaching case, take a simple calculator as an example to tell about Android interface design and event handling; for experimental case, optional examples can be standard weight calculator, standard height calculator, the user login interface, questionnaires procedures.

Android Data Storage Technology: for teaching case, introduce SharedPreference by the example 
of saving game score, or illustrate SQLite by giving example of mobile phone address book; for experimental case, optional examples can be improving mobile phone address book, moving diary or English test bank system.

Multi-threading and Android graphic design: for teaching cases, multithreading can be explained by examples of simple animation, drawing board, pinball game, Android drawing and event-based callback response; for experimental case, optional image rendering, drawing sine curve, drawing cosine curve, image browser, simple flight games. Teacher should provide the corresponding image material.

BroadcastReceiver, Service and ContentProvider: for teaching case, illustrate the usage of Service by the example of music player; for experimental case, multimedia player development, mobile phone alarm clock service, using ContentProvider to share mobile phone address book.

Students' course design is arranged in the late period of the course and teachers provide information system topics such as the library mobile information service system, campus mobile information service system, and online bookstore mobile service system. Students ought to integrate and apply the completed chapter assignment and then make appropriate expansion to complete the course design. Software project management can be used as the main line to manage every aspect in the entire mobile development process, from requirements analysis, design, coding, testing to the on-line acceptance check, which can enhance students' programming skills and at the same time, foster their project development synthesized accomplishment. After the initial exercise and training, competent students should be encouraged to participate in Android application Development Challenge of Chinese college students. Via autonomous and independent topic selection, students may pursue innovative and practical ideas to strengthen their hands-on ability and creative consciousness.

\section{Establishment of Three-dimensional Assessment System}

For programming and development courses, how to reduce or even prevent students' plagiarism behavior of the code is an unavoidable problem. Similarly, in the mobile application development course, the appraisal method to more accurately test the students' learning level is a real problem worthy of study.

In order to reduce the code plagiarism and other negative phenomena, improve students' learning initiative, this project builds a multi-dimensional assessment method, which takes students, teachers and student groups as multiple evaluation subject, learning attitude as multidimensional assessment content, and combines daily assignment, lab assignments, computer online exam as summative assessment and process assessment.

Assessment process is divided into three phases: examination preparation, project examination, project evaluation. Examination preparation phase needs assessing project design, students' team group, assessment environment preparation, assessment requirements and cautions announcement. In project appraisal stage teachers need to pay close attention to the students' state and performance, including the division of the organization, the team collaboration, project realization process and other aspects of students. The project assessment should not only base on the completion of project as the sole evaluation criterion.

Evaluation of the project includes the following aspects: (1) the accomplishment of the project, comprehensively testing students' master of knowledge and skills; (2) the completion of project design and document, comprehensively testing students' needs analysis and other aspects; (3) the arrangement of time, the shorter time the project is completed, the more rational organization and role assignment, the better member collaboration, the higher proficiency in knowledge and skills. In order to reduce students' plagiarism, questioning and answering can be adopted as course design scoring method.

\section{Conclusion}

By completing information system application program on Android mobile development platform, we aims to enable students to gradually master the latest and most popular smart mobile development technology and development skills. The implementation of information system 
project-oriented experiment mode of operation can fully integrate students' software engineering project management ideas with information system design and practice courses, so as to enhance students' engineering accomplishment of communication, collaboration, division of labor and cooperation. Project outcomes also apply to other related specialties, such as training e-commerce mobile development talents or training computer science and technology talents.

Through participation in national academic conferences and exchange of experiences with other universities, the research results can be further perfected and expanded. Promotion of the project results will help improve the quality of mobile development talent training, solve the problem of disjunction between information management and information system specialty theory teaching and social needs, hence improve the quality of teaching and personnel training, and cultivate high-quality and innovative talents to meet the needs of society. The results of the project also have high reference and promotional value for colleges and universities of the same kind.

\section{Acknowledgement}

In this paper, the research was sponsored by by Teaching and Research Reform Program of Yanshan College of Shandong University of Finance and economics, A Project of Shandong Province Higher Educational Science and Technology Program (Project No. J15LN56).

\section{References}

[1] www.xinchou.cn

[2] http://www.chinahrd.net/article/2014/04-29/24879-1.html

[3] ZHANG Yun-peng, ZHU Hong, LI Hui-fang, An Analysis of the Construction of Information Management \& Information System Specialty in Universities, Theory and Practice of Education, Vol.32, No.3, pp18-20, 2012.

[4] Hongxia Li, Junming Chen, A Teaching Reform thinking on Project Driving of University Information Management Courses, 2012 International Conference on Education Reform and Management Innovation, 2013.

[5] Xiao Yong, A discourse on Course of Knowledge Management as the Specialized Subject of Information Management as Colleges, Vol.50, No.3, March, 2006.

[6] Niu Li, YIN Fan, Talents Training Practice of Innovative Entrepreneurship Based on School-enterprise Integration_-The case of IOS Mobile Talents Development, Vocational and technical education, Vol.35 No.8, 2014.

[7] Li Xin-hui, SHEN Yin-yue, Vocational Course Design for Android Application Development Based on Learning by Doing, Computer Knowledge and Technology, Vol.10, No.18, June 2014. 